\title{
Sensitivitas, Spesifisitas, dan Akurasi Pengukuran Kontraksi Uterus Kala I Fase Aktif Ibu Bersalin Menggunakan Tokodinamometer
}

\author{
Lina Darmayanti Bainuan,, ${ }^{1}$ Farid Husin, ${ }^{2}$ Anita Deborah Anwar, ${ }^{2}$ Achmad Arifin, ${ }^{3}$ Firman F. Wirakusumah ${ }^{2}$ \\ ${ }^{1}$ Akademi Kebidanan Griya Husada Surabaya, Indonesia, ${ }^{2}$ Departemen Obstetri dan Ginekologi \\ Fakultas Kedokteran Universitas Padjadjaran/Rumah Sakit Dr. Hasan Sadikin Bandung, Indonesia, \\ ${ }^{3}$ Departemen Teknik Biomedik Institut Teknologi Sepuluh Nopember Surabaya, Indonesia
}

\begin{abstract}
Abstrak
Pada umumnya pemeriksaan kontraksi uterus dilakukan dengan menekan fundus uteri, namun demikian cara tersebut menyebabkan ketidaknyamanan dan hanya dapat mengetahui frekuensi kontraksi sedangkan durasi dan intensitas kontraksi pengukurannya bersifat subjektif. Cara lain yang digunakan adalah menggunakan Kardiotokografi, namun harganya mahal danl lebih sulit untuk menginterpretasikan hasil. Tokodinamometer dapat digunakan untuk menilai kemajuan persalinan karena dapat dibaca langsung, sederhana, dan harga terjangkau sehingga dapat digunakan di komunitas. Penelitian ini bertujuan mengukur sensitivitas, spesifisitas, dan akurasi tokodinamometer dalam mengukur kontraksi uterus kala I fase aktif pada ibu bersalin. Rancangan penelitian merupakan studi observasional analitik dengan desain potong lintang. Sampel penelitian berjumlah 47 orang yang memenuhi kriteria inklusi di Rumah Sakit Khusus Ibu dan Anak Kota Bandung dengan teknik concecutive sampling. Pengambilan data dengan mengukur kontraksi uterus menggunakan tokodinamometer dan kardiotokografi (KTG) diukur secara bersamaan sebanyak 2 kali. Analisis menggunakan uji Wilcoxon dan uji diagnostik. Hasil penelitian didapatkan, frekuensi dan intensitas kontraksi uterus tidak terdapat perbedaan $(p>0,05)$, sedangkan durasi kontraksi terdapat perbedaan bermakna $(p<0,05)$ antara ibu bersalin kala I fase aktif yang diukur menggunakan tokodinamometer dan KTG. Tokodinamometer memiliki nilai sensitivitas $(90,47 \%)$, spesifisitas (78,26 \%), dan akurasi $(87,21 \%)$. Simpulan, tokodinamometer dapat digunakan untuk pemantauan kontraksi uterus di komunitas.
\end{abstract}

Kata kunci : Fase aktif, kontraksi uterus, tokodinamometer

\section{Sensitivity, Specificity and Accuracy Measurement of Kala I Uterus Contraction Maternity Active Maternal Phase using Tocodynamometer}

\begin{abstract}
Examination of uterine contractions is generally done by pressing the uterine fundus. This method can cause discomfort and can only know the frequency of contraction while the duration and intensity of contraction measurement is subjective so as to cause imprecise in making decisions early during labor. Labor monitoring should use cardiotocography, but it is expensive, more difficult to interpret results. Though contraction assessment is important to assess the progress of labor, so that needed tools that can be used in the community. This study aimed to analyze the sensitivity, specificity and accuracy of tocodynamometer in measuring uterine contraction in the first stage on the active phase of parturient. The research design is an analytic observational study with Cross sectional design. The sample of this research were 47 people who fulfill the inclusion criteria at RSKIA Bandung, with concecutive sampling technique. Intake of data by measuring uterine contractions using tocodynamometer and cardiotocography measured simultaneously as much as 2 times or according to mother condition. The analysis used the Wilcoxon's test, and the diagnostic test. The results showed that the frequency and intensity of uterine contractions did not differ $(\mathrm{p}>0.05)$, whereas the duration of contraction was significantly different with $\mathrm{p}=0.012(\mathrm{p}<0.05)$ between maternal women and the active phase measured using tocodynamometer and CTG. The tocodynamometer has a sensitivity value $90.47 \%$, specificity $78.26 \%$, and accuracy $87.21 \%$, so that the tocodynamometer has the same sensitivity, specificity and accuracy close to Cardiotocography as the gold standard. In conclusion, tocodynamometer can be used for monitoring uterine contractions i community midwifery.
\end{abstract}

Key words: Active phase, uterine contractions, tocodynamometer

Korespondensi: Lina Darmayanti Bainuan, S.ST, M.Keb, Akademi Kebidanan Griya Husada Surabaya, Jalan Dukuh Pakis II Baru No. 110, Dukuh Pakis, Surabaya 60225, Jawa Timur, Indonesia, E-mail: linadarmayanti@gmail.com 


\section{Pendahuluan}

Persalinan ialah serangkaian proses pengeluaran janin yang dimulai dengan kontraksi dan ditandai dengan perubahan progresif pada serviks dan diakhiri oleh pelahiran plasenta. Kontraksi uterus merupakan suatu aktivitas miometrium selama persalinan aktivitas miometrium itu mengalami peningkatan dan perubahan dalam pola kontraktilitas dari kontraktur (tahan lama dan aktivitas rendah) ke kontraksi (intensitas dan aktivitas tinggi) sehingga mengakibatkan penipisan dan juga dilatasi serviks uterus serta penurunan kepala janin. ${ }^{1}$ Kontraksi uterus pada persalinan fase aktif lebih nyeri, berlangsung dengan rata-rata durasi 60 detik, intensitas $>25-$ $50 \mathrm{mmHg}$, diakhir fase aktif $80 \mathrm{mmHg}$, frekuensi menjadi lebih sering 3-5 kali/10 menit, berbeda dengan kontraksi uterus pada kala I fase leten intensitasnya kurang. ${ }^{2,3}$

Pemantauan persalinan meliputi kemajuan persalinan, keadaan janin, dan juga ibu dalam manajemen persalinan merupakan salah satu aspek penting. ${ }^{4}$ Berdasar atas hasil penelitian kontraksi yang terlalu lama atau sangat kuat dan frekuensinya sering akan menimbulkan masalah seperti hipoksia janin.5,6 Persalinan yang sudah memasuki fase aktif secara normal kontraktilitas uterus akan semakin meningkat yang meliputi frekuensi, durasi, dan intensitas. Ibu bersalin pada fase aktif akan mengalami hipotonik atau hipertonik yang akan memengaruhi kemajuan persalinan serta memengaruhi kondisi janin.,7

Penggunaan kardiotokografi (KTG) berdasar atas beberapa penelitian yang menunjukkan bahwa KTG untuk mengidentifikasi kontraksi uterus pada persalinan mempunyai sensitivitas dan akurasi lebih rendah apabila dibanding dengan electrohysterography dan intrauterine pressure catheter (IUPC) ${ }^{8,9}$ Kardiotokografi atau tokodinamometer kurang efektif dipakai pada ibu bersalin dengan obesitas (indeks massa tubuh atau IMT >35). ${ }^{13,14}$ Namun pemantauan dengan Catheter Intrauterine (IUPC) kurang dianjurkan untuk dipergunakan karena invasif memiliki risiko terjadinya ketuban pecah dan memengaruhi kondisi janin..$^{8,12}$

Kardiotokografi sebuah metode elektronik yang penggunaannya dengan cara eksternal. Kardiotokografi secara simultan akan merekam denyut jantung janin atau DJJ, gerakan janin, dan kontraksi uterus sebagai metode untuk menilai kesejahteraan janin, terutama pada masa kehamilan dengan peningkatan risiko komplikasi. Pemantauan terus menerus dengan KTG pada Intrapartum dengan manajemen yang tepat dapat mengurangi kejadian bayi lahir dengan hipoksia. Kardiotokografi merupakan perangkat elektronik dengan sensor "strain guard" yang digunakan secara eksternal untuk mendeteksi kontraktilitas miometrium sesuai dengan perubahan aktivitas uterus. ${ }^{10-12}$

Bidan di komunitas atau pelayanan kesehatan pertama selama ini melakukan pemeriksaan kontraksi pada uterus dengan menekan rahim di fundus uteri saat kontraksi. Pemantauan kontraksi dengan cara sederhana (konvensional) dengan palpasi ini hanya mampu mengukur frekuensi kontraksi, sedangkan intensitas dan durasi kontraksi hasilnya bersifat subjektif, keadaan ini memberikan ketidaknyamanan pada ibu. Pemeriksaan kontraksi dengan perabaan di abdomen berdasar atas penelitian Barnea dkk. ${ }^{13}$ diketahui bahwa pemeriksaan kontraksi memberikan efektivitas hasil pemeriksaan yang kurang karena memerlukan pengalaman dan keterampilan sehingga kesalahan pemeriksaan lebih besar. Selain itu, pemantaun kontraksi secara sederhana dengan palpasi ini hanya dapat memeriksa frekuensi kontraksi, intensitas, dan durasi kontraksi belum dapat ditentukan secara tepat.

Penolong persalinan paling banyak adalah bidan $(68,6 \%)$. Jadi, bidan memiliki peranan yang penting pada ibu dalam masa kehamilan dan persalinan. ${ }^{14}$ Bidan bertugas mendampingi ibu selama proses persalinan sehingga penting menilai kontraksi uterus dengan lebih baik, tidak hanya menilai frekuensi uterus, tetapi dapat menilai intensitas atau kekuatan dan lama kontraksi uterus dengan akurat. Ketidakakuratan pengukuran kontraksi uterus ini akan dapat berpengaruh pada bidan untuk dapat mengambil keputusan secara dini dan tepat untuk menjaga kesehatan ibu dan juga janin.

Pemantauan kontraksi uterus yang lebih akurat mempergunakan KTG yang sekaligus memeriksa kondisi janin, tetapi penggunaan KTG baru di rumah sakit tertentu karena biaya pengadaannya mahal, kurang mobile, serta perlu pelatihan karena tidak mudah untuk pembacaan hasil KTG yang terlihat dalam bentuk grafik pada kertas print out KTG. Oleh karena itu, telah dicoba pembuatan alat yang noninvasif, dapat menilai kontraksi, dapat dibaca langsung, bentuknya sederhana, dan harga terjangkau, yaitu tokodinamometer.

Tokodinamometer adalah suatu perangkat elektronik yang dikembangkan untuk mengukur aktivitas miometrium (kontraksi uterus), menggunakan sensor tekanan pada transduser yang dipergunakan secara eksternal untuk 
mendeteksi kontrakstilitas miometrium sesuai dengan perubahan aktivitas uterus. Penelitian ini bertujuan mengukur sensitivitas, spesifisitas dan akurasi tokodinamometer dalam mengukur kontraksi uterus kala I fase aktif pada ibu bersalin.

\section{Metode}

Rancangan pada penelitian merupakan studi observasional analitik dengan desain potong lintang. Penelitian ini sudah mendapat izin penelitian dari Komite Etik Penelitian Fakultas Kedokteran Universitas Padjadjaran No. 594/ UN6.C1.3.2/KEPK/PN/2016. Subjek penelitian sebanyak 47 orang ibu bersalin kala I fase aktif dengan IMT normal di Rumah Sakit Khusus Ibu dan Anak (RSKIA) Bandung pada bulan OktoberDesember 2016. Teknik pengambilan sampel dalam penelitian ini adalah concecutive sampling. Tokodinamometer merupakan alat yang aman dan tepat guna, tranduser yang berbahan acrylic dan terdiri atas perangkat lunak dan perangkat keras yang telah dilakukan uji kalibarsi/uji coba terlebih dahulu pada ibu dan pada ibu bersalin sejak November 2015. Tokodinamometer ini dirancang bekerjasama dengan Teknik Elektro Biomedik Institut Teknologi Sepuluh Nopember (ITS) Surabaya.

Pengambilan data penelitian ini dilakukan dengan mengukur kontraksi uterus memakai tokodinamometer dan kardiotokografi (Toco) merk Philips Avalon FM30 sebagai baku emas yang diukur secara bersamaan sebanyak 2 kali atau sesuai kondisi ibu. Pengukuran dilakukan pertama kali saat ibu masuk kala I fase aktif (pembukaan serviks 4-10 cm) selama 10 menit
Tabel 1 Distribusi Frekuensi Karakteristik Ibu Bersalin Kala I Fase Aktif

\begin{tabular}{lcc}
\hline Karakteristik & $\begin{array}{c}\text { Frekuensi } \\
\text { (n=47) }\end{array}$ & $\begin{array}{c}\text { Persentase } \\
\text { (\%) }\end{array}$ \\
\hline Usia (tahun) & & \\
$<20$ & 8 & \\
$20-30$ & 28 & 17 \\
$>30$ & 11 & 60 \\
Rerata & 25,72 & 23 \\
Median & 26,00 & \\
Rentang & $15-39$ & \\
Paritas & & 5 \\
$\quad$ Primigravida & 24 & 45 \\
$\quad$ Multigravida & 21 & 4 \\
Grandemulti & 2 & \\
IMT & & - \\
Rata-rata & 24,03 & - \\
Median & 24,47 & - \\
Rentang & $20,00-25,97$ & \\
\hline
\end{tabular}

dan diukur kembali 30 menit sampai 1 jam kemudian dari waktu pengukuran pertama untuk medapatkan data kembali Analisis menggunakan uji Wilcoxon untuk menilai perbedaan kontraksi uterus oleh karena data berdistribusi tidak normal dan uji diagnostik yang sebelumnya data berskala numerik ditetapkan cut-off point dan area under curve (AUC) dengan cara receiver operating characteristic (ROC).

\section{Hasil}

Pada 47 ibu bersalin kala I fase aktif didapatkan 86 kali pengukuran kontraksi. Karakteristik ibu bersalin kala I fase aktif di RSKIA sebagian besar

Tabel 2 Perbedaan Hasil Pengukuran Kontraksi Uterus Kala I Fase Aktif pada Ibu Bersalin Menggunakan Tokodinamometer dengan Kardiotokografi

\begin{tabular}{lccc}
\hline Kontraksi Uterus & Tokodinamometer(n=86) & KTG (n=86) & $\mathbf{p}^{*}$ \\
\hline Frekuensi & $5,09(1,50)$ & $5,02(1,59)$ & 0,063 \\
X (SD) & 5,00 & 5,00 & \\
Median & $2-10$ & $2-10$ & \\
Rentang & & & $0,012^{* *}$ \\
Durasi & $49,19(11,3)$ & $48,66(15,84) 45,5$ & \\
X (SD) & 50,85 & $20-120$ & \\
Median & $30-80$ & & 0,212 \\
Rentang & & $49,6(14,28)$ & 46,9 \\
Intensitas & $52,04(15,88)$ & $23-93,6$ & \\
X (SD) & 50,62 & \\
Median & $26-87,5$ & & \\
Rentang &
\end{tabular}

Keterangan:*Uji Wilcoxon dengan nilai $\mathrm{p}<0,05$ berbeda bermakna, ${ }^{* *}=$ berbeda 
Lina D. Bainuan dkk.: Sensitivitas, Spesifisitas, dan Akurasi Pengukuran Kontraksi Uterus Kala I Fase Aktif Ibu Bersalin

Tabel 3 Cut-off Point Frekuensi, Durasi, Intensitas Kontraksi Uterus Kala I Fase Aktif Pada Ibu Bersalin

\begin{tabular}{lccccccccc}
\hline $\begin{array}{c}\text { Kontraksi } \\
\text { Uterus }\end{array}$ & $\begin{array}{c}\text { Nilai } \\
\text { Cut-off } \\
\text { Point }\end{array}$ & $\begin{array}{c}\text { Tokodina- } \\
\text { mometer }\end{array}$ & CTG & $\begin{array}{c}\text { Sensitivitas } \\
\mathbf{( \% )}\end{array}$ & $\begin{array}{c}\text { Spesifisitas } \\
\mathbf{( \% )}\end{array}$ & $\begin{array}{c}\text { Akurasi } \\
\mathbf{( \% )}\end{array}$ & $\begin{array}{c}\text { NDP } \\
\text { (\%) }\end{array}$ & $\begin{array}{c}\text { NDN } \\
\text { (\%) }\end{array}$ & Nilai p \\
\hline Frekuensi & $>5$ & 25 & 25 & 84,37 & 100 & 97,67 & 100 & 91,5 & $<0,001$ \\
& $\leq 5$ & 61 & 61 & & & & & & \\
Durasi & $<33$ & 5 & 6 & 75 & 96,34 & 90,69 & 50 & 98,8 & 0,0097 \\
& $\geq 33$ & 81 & 80 & & & & & & \\
Intensitas & $<54$ & 42 & 49 & 80 & 43,21 & 87,2 & 8,0 & 97,2 & 0,9342 \\
& $\geq 54$ & 44 & 37 & & & & & & \\
\hline
\end{tabular}

berusia 20-30 tahun (60\%), dan sebagian besar primigravida sebanyak 24 orang $(51 \%)$. indeks massa tubuh (IMT) ibu bersalin yang dijadikan subjek penelitian adalah Ibu dengan IMT normal rata-rata $24,03 \mathrm{~kg} / \mathrm{m}^{2}$ (Tabel 1 ).

Perbedaan hasil pengukuran kontraksi uterus kala I fase aktif pada ibu bersalin menggunakan tokodinamometer dan KTG diketahui bahwa frekuensi kontraksi uterus dan intensitas tidak terdapat perbedaan $(p>0,05)$ antara ibu bersalin kala I fase aktif yang diukur menggunakan Tokodinamometer dan KTG. Durasi kontraksi terdapat perbedaan yang bermakna dengan nilai $\mathrm{p}=0,012(\mathrm{p}<0,05$; Tabel 2).

Analisis untuk mengetahui sensitivitas, spesifisitas, dan akurasi tokodinamometer, yaitu dengan uji diagnostik yang sebelumnya telah ditentukan cut-off point dan nilai area under curve (AUC) menggunakan receiver operating characteristics (ROC). Hasil penelitian diketahui bahwa nilai AUC pengukuran frekuensi yang diperoleh adalah sebesar $85,7 \%$, hasil tersebut secara statistik telah menunjukkan nilai AUC tergolong baik. Nilai AUC pengukuran durasi kontraksi uterus sebesar 75,9\% secara statistik memperlihatkan nilai AUC tergolong sedang. Nilai AUC pengukuran intensitas kontraksi uterus yang diperoleh sebesar $51,5 \%$, secara statistik menunjukkan nilai AUC tergolong sangat lemah. Berdasarkan nilai AUC, didapatkan cut-off point dari frekuensi kontraksi yang optimal adalah $>5 \mathrm{x} / 10$ menit dengan sensitivitas $84,37 \%$ dan spesifisitas sebesar $100 \%$. Nilai duga positif (NDP) 100\%, Nilai Duga Negatif (NDN) 91,5\% dan akurasi sebesar 97,67\%. Hasil uji statistik chi kuadrat bermakna $p<0,001$ (nilai $p \leq 0,05$ ).

Cut-off point durasi kontraksi yang optimal adalah $<33$ detik dengan sensitivitas sebesar $75 \%$ dan spesifisitas sebesar 96,34\%. Nilai duga positif $50 \%$, NDN 98,8\%, dan akurasi 90,69\%. Hasil uji statistik chi kuadrat bermakna $\mathrm{p}<0,001$ (nilai $\mathrm{p} \leq 0,05$ ). Dilihat dari kurva ROC diatas juga didapatkan cut-off point intensitas kontraksi yang optimal ialah $<54 \mathrm{mmHg}$ dengan sensitivitas sebesar $80 \%$ dan spesifisitas $43,21 \%$. Nilai duga positif (NDP) 8,0\%, NDN 97,2\%, dan akurasi $87,2 \%$. Hasil uji statistik Chi kuadrat tidak bermakna $\mathrm{p}>0,001$ (nilai $\mathrm{p} \geq 0,05$; Tabel 3). Analisis selanjutnya dilakukan uji diagnostik Tokodinamometer dalam mengukur kontraksi uterus kala I fase aktif pada ibu bersalin, yaitu sensitivitas $90,47 \%$, spesifisitas $78,26 \%$, dan akurasi 87,21\% (Tabel 4).

Tabel 4 Uji Diagnostik Tokodinamometer dalam Mengukur Kontraksi Uterus Kala I Fase Aktif Pada Ibu Bersalin

\begin{tabular}{llccc}
\hline \multirow{2}{*}{$\begin{array}{c}\text { Hasil pengukuran Kontraksi Uterus dengan } \\
\text { Tokodinamometer }\end{array}$} & \multicolumn{2}{c}{$\begin{array}{c}\text { Standar Baku Emas } \\
\text { Hasil Pengukuran Kontraksi } \\
\text { Uterus dengan KTG }\end{array}$} & Total \\
& Tidak normal & Normal & \\
\hline \multirow{2}{*}{$\begin{array}{l}\text { Kontraksi } \\
\text { Uterus }\end{array}$} & Positif dengan pengukuran abnormal & $57^{\mathrm{a}}$ & $5^{\mathrm{b}}$ & 62 \\
& Negatif dengan pengukuran normal & $(90,47 \%)$ & $(8,1 \%)$ & $(72,10 \%)$ \\
& & $6^{\mathrm{c}}$ & $18^{\mathrm{d}}$ & 24 \\
& Jumlah & $(25,0 \%)$ & $(78,26 \%)$ & $(27,90 \%)$ \\
& & $(100 \%)$ & $(100 \%)$ & $(100 \%)$ \\
\hline
\end{tabular}



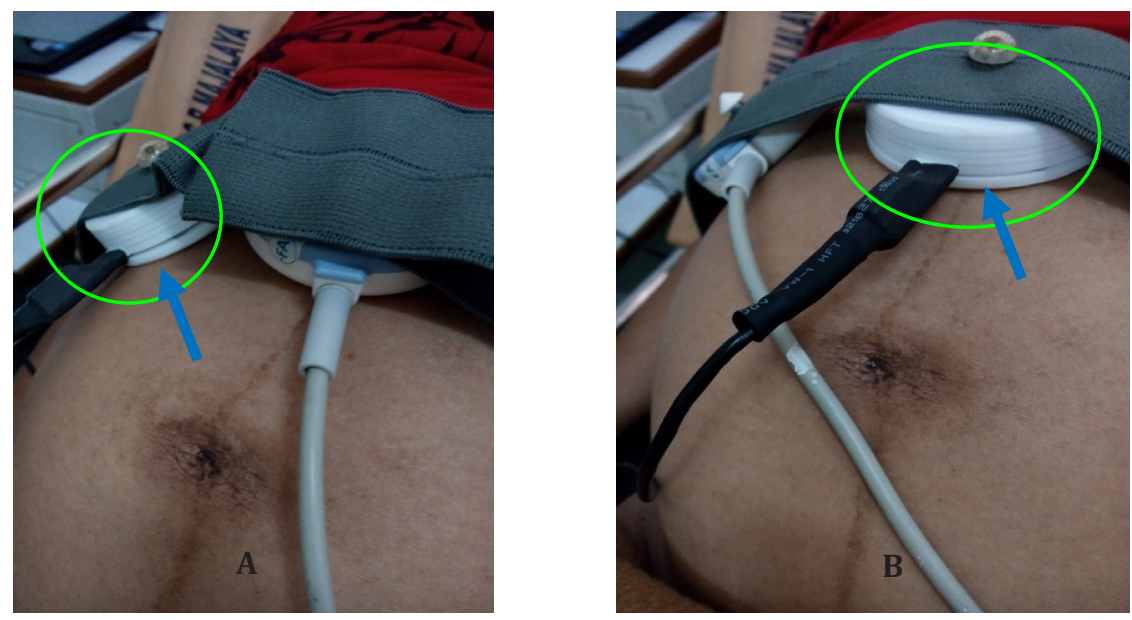

Gambar 1 Pengukuran Kontraksi Uterus dengan KTG dan Tokodinamometer yang Dilakukan Sebanyak 2 kali dengan Perubahan Letak Transduser (A ke B). Tranduser Tokodinamometer adalah yang Ditandai (lingkaran-panah)

\section{Pembahasan}

Pengukuran kontraksi uterus dilakukan dengan tokodinamometer dan KTG yang sudah diukur secara bersamaan selama 10 menit (Gambar 1). Hasil pengukuran tokodinamometer dan KTG diinterpretasikan melalui hasil print out kedua alat tersebut (Gambar 2). Karakteristik ibu diambil dari data rekam medis untuk menentukan IMT. Indeks massa tubuh subjek dalam kategori normal dengan rata-rata IMT $24,03 \mathrm{~kg} / \mathrm{m}^{2}$ yang berarti lemak subkutan dalam perut subjek tidak terlalu tebal yang dapat memengaruhi hasil pengukuran karena jarak antara uterus dan tranduser untuk menangkap gelombang tekanan listrik myometrium saat berkontraksi. Faktor usia dan IMT akan memengaruhi juga proses persalinan. Hal ini sesuai dengan hasil penelitian Zaiki dkk. ${ }^{15}$ yang menyatakan bahwa kemajuan persalinan dari 4-10 $\mathrm{cm}$ pada nullipara akan lebih cepat dengan bertambahnya usia ibu sampai usia 40 tahun, yaitu median 8,5 jam dibandingkan yang berusia 20-29 tahun dengan median 7,8 jam dan 7,4 jam pada ibu dengan usia 30-39 tahun. Hasil Penelitian Carlson dkk. ${ }^{16}$ di Amerika diketahui bahwa ibu bersalin dengan

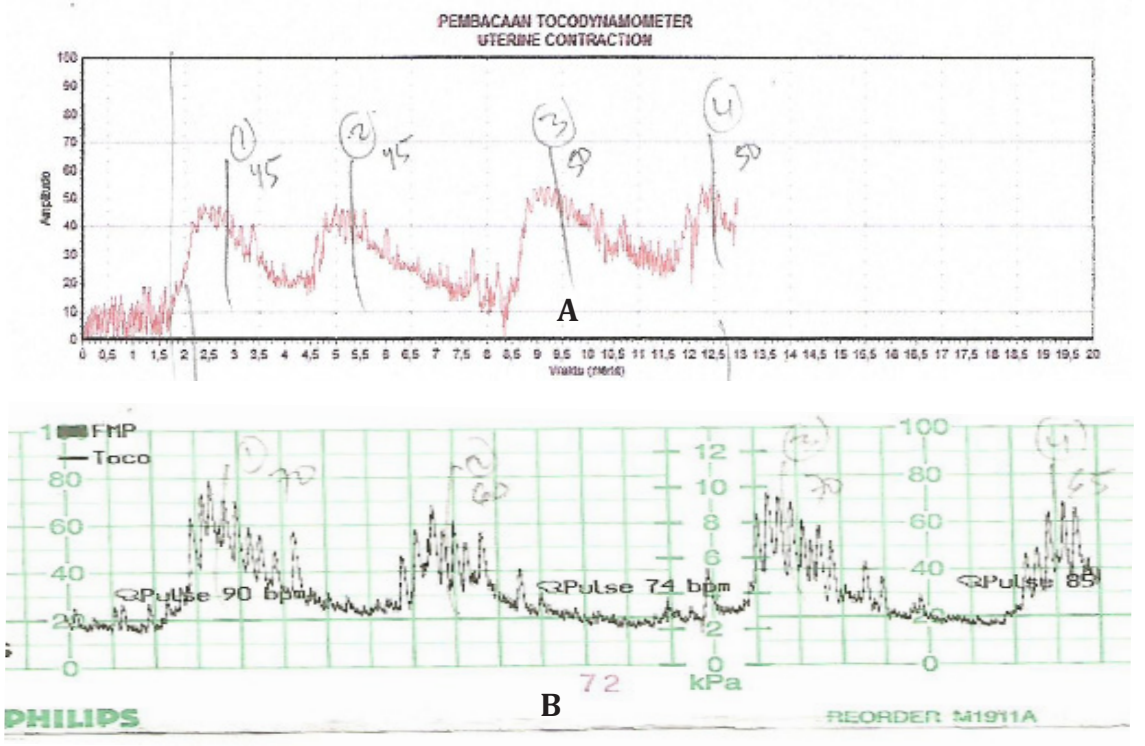

Gambar 2 Hasil Grafik Pengukuran Kontraksi Persalinan Kala I Fase Aktif (A) Tokodinamometer dan (B) Kardiotografi (KTG) 
obesitas berhubungan dengan perubahan pada plasenta, serviks, dan miometrium yang dapat memperlambat persalinan dan juga sinkronisasi kontraksi uterus. Hasil penelitian dua kohort prospektif, peningkatan IMT ibu secara klinis berhubungan dengan protracted labor. Waktu yang dibutuhkan terjadi dilatasi penuh pada ibu obesitas (IMT $\geq 40 \mathrm{~kg} / \mathrm{m}^{2}$ ) secara signifikan lebih lama dari ibu dengan IMT normal. ${ }^{16,17}$

Hasil analisis uji beda dengan Wilcoxon, pengukuran frekuensi dan intensitas kontraksi uterus menggunakan KTG dan tokodinamometer diketahui tidak berbeda hasilnya, sedangkan pengukuran durasi kontraksi uterus berbeda. Walaupun ada perbedaan hasil pengukuran durasi kontraksi uterus kala I fase aktif yang diukur dengan KTG dan tokodinamometer, tetapi tidak terlalu signifikan, yaitu perbedaannya dengan median $(45,5$ vs 50,85$)$, rentang $(20-120$ vs 30-80) atau tokodinamometer mendeteksi durasi kontraksi kala I fase aktif waktunya lebih lama (mean 5,35 detik dan rentang 10-40 detik) dibanding dengan KTG. Perbedaan durasi dapat terjadi karena penempatan transduser, ketebalan lemak subkutan, dan tekanan dinding rahim. Penempatan transduser ini memengaruhi dalam penangkapan gelombang kontraktil yang secara fisiologis, kontraksi normal pada persalinan berawal dari dekat salah satu tuba falopii yang melekat ke uterus yang berfungsi sebagai pemicu "pacemaker" dan pacemaker sebelah kanan lebih dominan dari sebelah kiri dan memulai sebagian besar gelombang kontraksi. ${ }^{18}$

Berdasar atas kurva ROC diketahui bahwa nilai AUC pengukuran frekuensi kontraksi uterus sebesar 85,7\%, yang secara statistik nilai AUC tergolong baik. Jadi, apabila tokodinamometer digunakan untuk mengukur frekuensi kontraksi uterus pada kala I fase aktif pada 100 orang ibu bersalin maka hasil yang tepat akan diperoleh pada 86 orang ibu bersalin. Melalui kurva ROC, didapatkan cut off point frekuensi kontraksi yang optimal adalah $>5 \mathrm{x} / 10$ menit.

Berdasar atas kurva ROC diketahui bahwa nilai AUC pengukuran durasi kontraksi uterus yang diperoleh sebesar $75,9 \%$, secara statistik menunjukkan nilai AUC tergolong sedang, artinya apabila tokodinamometer digunakan untuk mengukur durasi kontraksi uterus pada kala I fase aktif pada 100 orang ibu bersalin maka hasil yang tepat akan diperoleh pada 76 orang ibu bersalin. Melalui kurva ROC juga didapatkan cutoff point durasi kontraksi yang optimal adalah $<33$ detik. Berdasar atas nilai akurasi sebesar $89,53 \%$, berarti secara statistik menunjukkan tokodinamometer termasuk kategori baik dalam mengukur durasi kontraksi uterus kala I fase aktif.

Berdasar atas kurva ROC pula bahwa nilai AUC pengukuran intensitas kontraksi uterus yang diperoleh sebesar $51,5 \%$, secara statistik menunjukkan nilai AUC tergolong sangat lemah, artinya bila tokodinamometer digunakan untuk mengukur intensitas kontraksi uterus pada kala I fase aktif pada 100 orang ibu bersalin, maka hasil yang tepat akan diperoleh pada 52 orang ibu bersalin. Dari kurva ROC juga didapatkan cut-off point intensitas kontraksi yang optimal $<54 \mathrm{mmHg}$.

Berdasar atas Tabel 3 pengukuran kontraksi uterus kala I fase aktif, pengukuran frekuensi kontraksi sudah baik sedangkan pengukuran durasi dan juga intensitas didapatkan bahwa Tokodinamoemeter dalam mengukur durasi yang tidak normal/sensitivitas lebih rendah hasilnya bila dibanding dengan mengukur durasi yang normal/spesifitas. Begitupun pada pengukuran intesitas kontraksi, tokodinamometer lebih tinggi hasilnya dalam mengukur intesitas yang tidak normal (sensitivitas 80\%) bila dibanding dengan intensitas yang normal (spesifisitas 43,21\%). Hasil ini dipengaruhi oleh kondisi ibu yang sebagian besar mendapatkan uterotonika, serta rasa sakit yang semakin meningkat yang dirasakan ibu menyebabkan ibu sering bergerak yang akhirnya dapat memengaruhi penangkapan tekanan oleh sensor transduser tokodinamometer dan KTG.

Hasil uji dari diagnostik tokodinamometer berdasar atas Tabel 4 dalam mengukur kontraksi uterus kala I fase aktif pada ibu bersalin diketahui nilai sensitivitas adalah $91,9 \%$ dan spesifisitas $78,26 \%$, dan akurasinya sebesar $87,21 \%$. Hasil uji diagnostik tersebut menunjukkan bahwa tokodinamometer ini dalam mengklarifikasi kontraksi uterus kala I fase aktif tidak normal pada kenyataannya 91,9\% benar-benar tidak normal. Selanjutnya, tokodinamometer dapat mengonfirmasi kontraksi ibu bersalin kala I fase aktif yang benar normal dan yang mengalami kontraksi uterus yang normal $(78,26 \%)$. Tokodinamometer ini termasuk kategori baik dalam mengukur kontraksi uterus kala I fase aktif. Beberapa penelitian diketahui bahwa KTG memiliki nilai sensitivitas sebesar 74-96,67\%, spesifisitas sebesar 72-93,33\%, NDP sebesar 60,90-84,20\%, NDN sebesar 21,30-69,91\%, akurasi sebesar $61,1-95 \% .^{8-10}$

Keadaan ini berarti tokodinamometer yang digunakan pada penelitian ini menunjukkan sensitivitas, spesifisitas dan juga akurasi yang mendekati terhadap kardiotokografi sebagai 
baku emas. Dengan demikian tokodinamometer direkomendasikan untuk digunakan khususnya pada ibu bersalin kala I fase aktif dengan IMT $19-26 \mathrm{~kg} / \mathrm{m}^{2}{ }^{18}$ Penelitian ini juga sesuai dengan penelitian yang dilakukan oleh Aina- Mumuney dkk. ${ }^{19}$ tokodinamometer efektif digunakan pada IMT yang normal, pengukuran kontraksi uterus perlu memperhatikan peningkatan IMT seorang ibu seiring dengan peningkatan usia kehamilan.

Tokodinamometer memiliki nilai sensitivitas, spesifisitas dan akurasi yang mendekati KTG sebagai standar baku emas dalam mengukur kontraksi uterus kala I fase aktif pada ibu bersalin didukung dengan harga yang terjangkau sehingga dapat dipergunakan secara luas di kebidanan komunitas. Namun, perlu dilakukan penelitian lebih lanjut pada populasi yang lebih heterogen dan pengukuran kontraksi pada fase atau tahapan persalinan lainnya (kontrasksi awal atau fase laten) serta pada IMT lebih (over weight dan obesitas) dan dengan jumlah subjek yang lebih banyak agar diketahui ketahanan alat tersebut.

\section{Daftar Pustaka}

1. Safdar AHA, Kia HD, Farhadi R. Physiology of parturition. Intl J Adv Biol Biomed Res. 2013;1(3):214-21.

2. Cunningham FG, Leveno KJ, Bloom SL, Hauth JC, Rouse DJ, Spong CY. Williams Obstetrics. Edisi ke-23. New York: Mc Graw Hill Medical; 2010.

3. Hadar E, Biron-Shental T, Gavish O, Raban 0 , Yogev Y. A comparison between electrical uterine monitor, tocodynamometer and intra uterine pressure catheter for uterine activity in labor. J Matern Fetal Neonatal Med. 2015;28(12):1367-74.

4. Shepherd A, Cheyne H. The frequency and reasons for vaginal examinations in labour. Australian College of Midwive. 2013;26:4954.

5. Bakker PC, Van Rijswijk S, van Geijn HP. Uterine activity monitoring during labor. J Perinat Med. 2007;35(6):468-77.

6. Pates JA, McIntire DD, Leveno KJ. Uterine contractions preceding labor. Obst Gynecol. 2007;110(3):566-9.

7. Moghaddam TG, Moslemizadeh N, Seifollahpour Z, Shahhosseini Z, Danesh M. Uterine contractions' pattern in active phase of labor as a predictor of failure to progress. Global J Health Sci. 2014;6(3):200-5.
8. Hayes-Gill B, Solomon M, Hassan S, Brown R, Mirza FG, Ommani S, dkk. Accuracy and reliability of uterine contraction identification using abdominal surface electrodes. Clin Med Insights: Women's Health. 2012;5:65-75.

9. Euliano TY, Nguyen MT, Darmanjian S, Mcgorray SP, Euliano N, Onkala A, dkk. Monitoring uterine activity during labor: a comparison of three methods. Am J Obstetri Gynecol. 2013;208(1):66e1-6.

10. Euliano TY, Nguyen MT, Marossero D, Edwards RK. Monitoring Contractions in obese parturients electrohysterography compared with traditional monitoring. Am J Obstet Gynecol. 2007;109(5):1136-40.

11. Bakker PCAM, Kurver PHJ, Kuik DJ, Geijn HPV. Elevated uterine activity increases the risk of fetal acidosis at birth. Am J Obstet Gynecol. 2007;196:313.e1-6.

12. Debdas AK. Practical cardiotocography: Jaype Brothers Med Publishers; 2013.

13. Barnea O, Luria O, Jaffa A, Stark M, E.Fox H, Farine D. Relations between fetal head descent and cervical dilatation during individual uterine contractions in the active stage of labor. J Obstetri Gynaecol. 2009;35 (4):654-9.

14. Kementerian Kesehatan RI. Riset Kesehatan Dasar. Badan Penelitian Pengembangan Kesehatan Kementerian Kesehatan RI. Jakarta. 2013.

15. Zaki MN, Judith U. Hibbard, Kominiarek MA.Contemporary Labor Patterns and Maternal Age. J Obstetri Gynaecol. 2013; 122(5):1018-24.

16. Carlson NS, Hernandez TL, Hurt KJ. Parturition dysfunction in obesity: time to target the pathobiology. Reprod Biol Endocrinol. 2015;13(35):1-14.

17. O'Reilly JR, Reynolds RM. The risk of maternal obesity to the long-term health of the offsping. Clin Endocrinol (Oxf). 2013;78(1):9-16.

18. Kominiarek MA, Zhang J, Vanveldhuisen P, Troendle J, Beaver J, Hibbard JU.. Contemporary labor patterns: the impact of maternal body mass index. Am J Obstet Gynecol. 2011;205(3):244.e1-8.

19. Aina-Mumuney A, Hwang K, Sunwoo N, Burd I, Blakemore K. The impact of maternal body mass index and gaestational age on detection of uterine contractions by tocodynamometry: a retrospective study. Reprod Sci. 2016;23(5):638-43. 